\title{
Micelle-in-Liposomes for Sustained Delivery of Anticancer Agents That Promote Potent TRAIL-Induced Cancer Cell Apoptosis
}

\author{
Zhenjiang Zhang, Sagar B. Patel and Michael R. King * \\ Department of Biomedical Engineering, Vanderbilt University, Nashville, TN 37212, USA; \\ zhenjiang.zhang@vanderbilt.edu (Z.Z.); sagar.patel@vanderbilt.edu (S.B.P.) \\ * Correspondence: mike.king@vanderbilt.edu
}

check for

updates

Citation: Zhang, Z.; Patel, S.B.; King, M.R. Micelle-in-Liposomes for Sustained Delivery of Anticancer

Agents That Promote Potent

TRAIL-Induced Cancer Cell

Apoptosis. Molecules 2021, 26, 157. https://doi.org/10.3390/molecules 26010157

Academic Editors: Drazen Raucher and Andrea Trabocchi

Received: 1 November 2020

Accepted: 29 December 2020

Published: 31 December 2020

Publisher's Note: MDPI stays neutral with regard to jurisdictional clai$\mathrm{ms}$ in published maps and institutional affiliations.

Copyright: (C) 2020 by the authors. Licensee MDPI, Basel, Switzerland. This article is an open access article distributed under the terms and conditions of the Creative Commons Attribution (CC BY) license (https:// creativecommons.org/licenses/by/ $4.0 /)$.

Abstract: Tumor necrosis factor (TNF)-related apoptosis-inducing ligand (TRAIL) induces cancer cell-specific apoptosis and has garnered intense interest as a promising agent for cancer treatment. However, the development of TRAIL has been hampered in part because most human cancer cells are resistant to TRAIL. A few small molecules including natural compounds such as piperlongumine (PL) have been reported to sensitize cancer cells to TRAIL. We prepared a novel type of nanomaterial, micelle-in-liposomes (MILs) for solubilization and delivery of PL. PL-loaded MILs were used to sensitize cancer cells to TRAIL. As visualized by cryo-TEM, micelles were successfully loaded inside the aqueous core of liposomes. The MILs increased the water solubility of PL by $\sim 20$ fold. A sustained PL release from MILs in physiologically relevant buffer over 7 days was achieved, indicating that the liposomes prevented premature drug release from the micelles in the MILs. Also demonstrated is a potent synergistic apoptotic effect in cancer cells by PL MILs in conjunction with liposomal TRAIL. MILs provide a new formulation and delivery vehicle for hydrophobic anticancer agents, which can be used alone or in combination with TRAIL to promote cancer cell death.

Keywords: TRAIL resistance; TRAIL sensitization; piperlongumine; micelle stability; drug delivery; complex nanomaterials; combination therapy

\section{Introduction}

Selective killing of cancer cells has been long pursued in the development of effective cancer treatment, while achieving little to no side effects. The cancer-specific apoptotic potential of tumor necrosis factor (TNF)-related apoptosis-inducing ligand (TRAIL) has attracted great attention among biologists and oncologists, with some studies using recombinant human TRAIL (rhTRAIL) reaching clinical trials [1]. TRAIL belongs to the TNF cytokine superfamily that specifically induces apoptosis in a broad spectrum of human cancer cell lines while sparing most healthy cells [2]. Our lab has developed TRAIL-conjugated liposomes that have proven to be successful in preventing cancer metastases by targeting and neutralizing tumor cells in the circulation in multiple murine tumor models [3-6], and in ex vivo experiments using cancer patient blood samples [7-9].

Despite the potent tumor-specific properties of TRAIL against a broad range of cancer cells, some cell lines have been found to be resistant to the effects of TRAIL [10]. To increase the therapeutic effectiveness of the protein against resistant cancer cells, a few small molecules including some chemotherapy drugs such as paclitaxel and bortezomib, and natural compounds such as piperlongumine (PL) and curcumin were reported for the sensitization of cancer cells to TRAIL [11-15]. PL was identified in a high throughput screening as a drug candidate that induces apoptosis selectively in cancer cells but has little apoptotic effect on normal cells [16]. In our previous studies, we demonstrated that PL sensitized certain cancer cells to potent TRAIL-mediated apoptosis $[15,17]$. However, due to the low water solubility of PL, a solubilization method is needed to further PL's application for TRAIL sensitization for future in vitro and in vivo studies. 
Polymeric micelles are nanoscale core-shell structures formed via self-assembly of amphiphilic copolymer in aqueous medium [18]. Polymeric micelles have been pursued as a promising drug delivery vehicle due to their capacity to hold water insoluble drugs inside the hydrophobic core of micelles [19]. Numerous polymeric micelle systems have been reported to increase drug solubility. However, micelles are known to dissociate and release encapsulated drug prematurely following dilution in cell culture medium or administration in the blood circulation [20].

In this paper, we report our efforts in the solubilization and delivery of PL using a novel type of nanomaterial, micelle-in-liposomes (MILs). PL was first solubilized with polymeric micelles, which were then encapsulated into the aqueous core of liposomes (Figure 1). Arguably considered the most successful drug delivery vehicle in clinical applications, liposomes have been engineered to avoid reticuloendothelial system (RES) trapping and enjoy a blood circulation time of $>20 \mathrm{~h}[21,22]$. The aim of containing drugloaded micelles inside of liposomes is to avoid micelle dissociation and premature drug release when they are diluted for use. We found potent apoptotic effects of PL-loaded MILs in combination with liposomal TRAIL in prostate cancer cells. MIL may be used as a general delivery vehicle for hydrophobic anticancer agents to promote TRAIL-induced cancer-specific apoptosis.

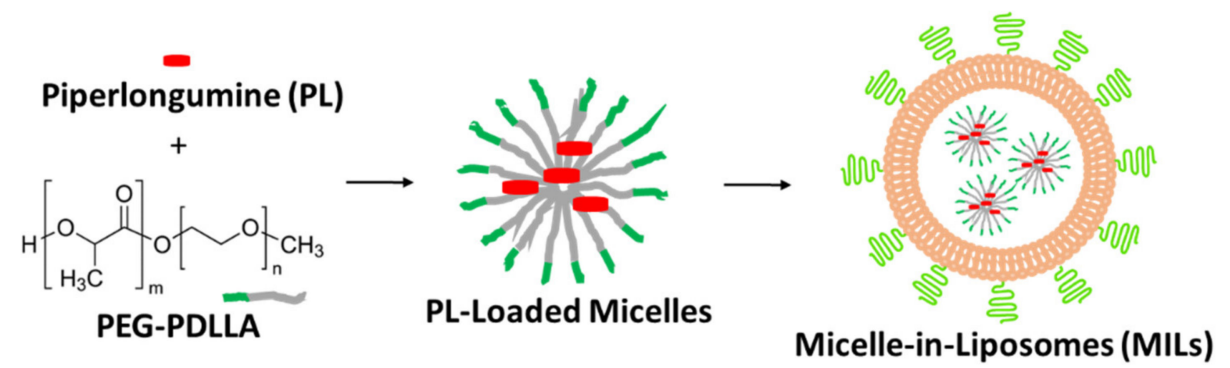

Figure 1. Schematic illustration of the formulation process of micelle-in-liposomes (MILs).

\section{Results}

\subsection{Preparation and Characterization of MILs}

In theory, micelles need to be sufficiently small for their passive encapsulation into unilamellar liposomes whose average size can be well controlled in the range of 50 to $200 \mathrm{~nm}$ [23]. We chose an amphiphilic polymer Poly(ethylene glycol) methyl ether-poly(D,L lactide) (PEG-PDLLA) with a molecular weight of $7000 \mathrm{kD}$, to prepare micelles with a solvent evaporation method. The as-prepared micelles were measured to be $\sim 22 \mathrm{~nm}$ in size on average by dynamic light scattering (DLS), which measured the hydrodynamic size of the micelles that include the hydrophilic corona, and $\sim 16 \mathrm{~nm}$ on average by TEM with negative staining, which measured only the hydrophobic core of the micelles (Figure 2A,C). To encapsulate the micelles into liposomes, a suspension of micelles was used to hydrate a lipid film that was prepared by evaporation of the organic solvent from the lipid solution. The mixture was extruded through a $200 \mathrm{~nm}$ polycarbonate filter to reduce the liposome size. The non-encapsulated micelles were successfully removed by size exclusion chromatography (SEC) based on the distinctive difference between the size of the micelles and liposomes as shown in Figure 1. The SEC purified mixture was found to be $\sim 167 \mathrm{~nm}$ on average by DLS (Figure 2D). Cryo-TEM revealed that the mixture consisted of both empty liposomes and MILs at a ratio of $\sim 3: 1$, i.e., micelles were successfully encapsulated into $\sim 25 \%$ of all liposomes. Notably, some MILs contained more than one micelle in their aqueous core (Figure 2D). As quantified by HPLC, the PL content in MILs reached $0.52 \mathrm{mg} / \mathrm{mL}$, $\sim 20$ times higher than the solubility of PL in water [24]. 

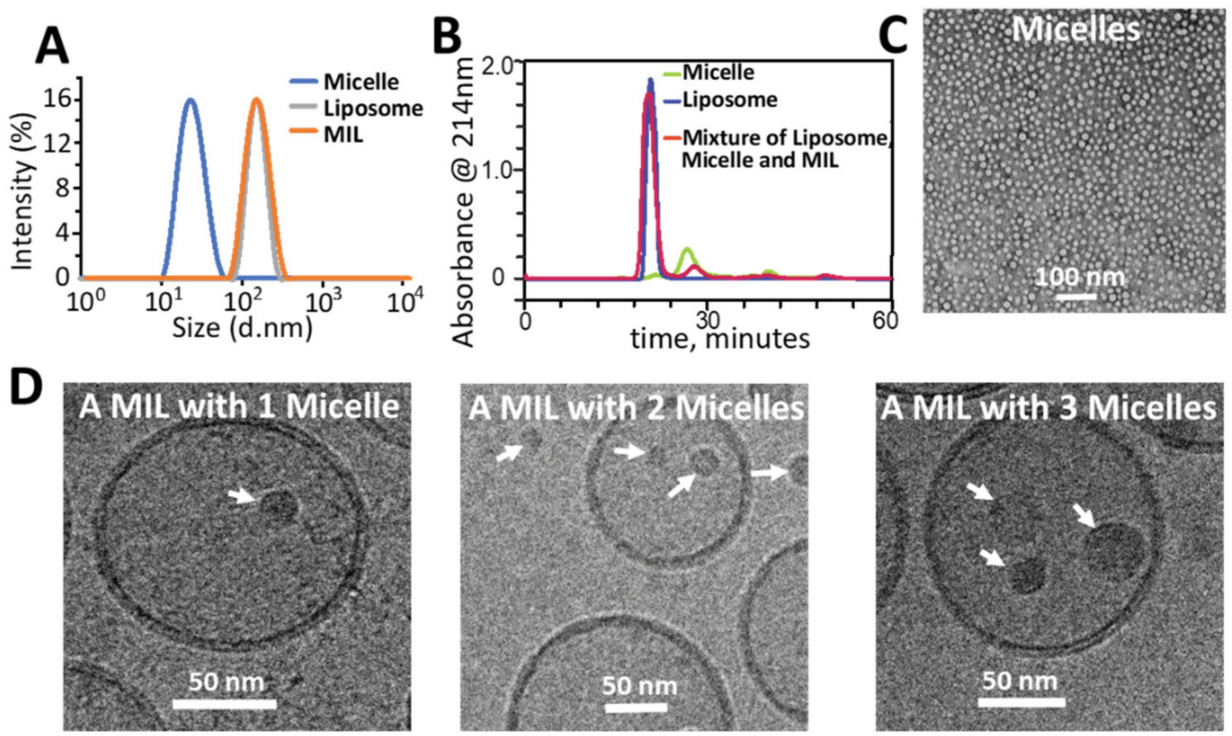

Figure 2. Physical characterization and purification of micelle-in-liposomes (MILs). (A) Size distribution of micelles, liposomes and MILs. (B) Separation of MILs from non-encapsulated micelles by size exclusion chromatography (SEC). (C) TEM of micelles. (D) Cryo-TEM of MIL containing 1, 2 or 3 micelles.

\subsection{Piperlongumine Release from PL MILs}

To compare their drug-release performance, PL micelles and PL MILs were placed in dialysis bags against a large amount of PBS at $37^{\circ} \mathrm{C}$. The PL concentration in the buffer was measured over time by HPLC. As shown in the release profile, nearly $100 \%$ of PL was released from the formulation of PL micelles within the first $6 \mathrm{~h}$, while PL MILs exhibited a sustained release for $>1$ week (Figure 3). These results support the idea that, in the MIL formulation, the liposomes prevented rapid drug release from the PL-loaded micelles.
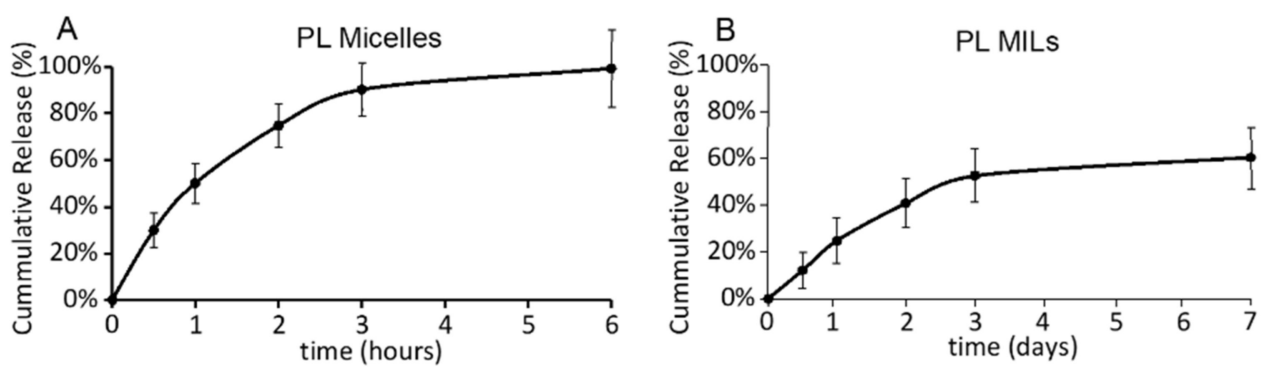

Figure 3. PL release profile from piperlongumine (PL) micelles (A) and PL MILs (B). PL micelles and PL MILs were placed in dialysis bags against a large amount buffer at $37^{\circ} \mathrm{C}$. PL released in the buffer was quantified by HPLC. Results are presented as the mean $\pm S E M, n=3$.

\subsection{Combination Cancer Cell Treatment with PL MILs and Liposomal TRAIL}

PL has been reported to induce apoptosis specifically in cancer cells by downregulating several anti-apoptotic proteins that are known to cause resistance in cancer cells to TRAILmediated apoptosis $[24,25]$. Our lab previously discovered that PL synergized with TRAIL to stimulate potent apoptosis in several cancer cells, suggesting the combination of PL and TRAIL as a novel paradigm for the treatment of cancer [15,17]. In the present study, we used PC3 and DU145 cells which exhibit medium and high sensitivity to TRAIL, respectively, to test the cytotoxic effects of PL MILs in combination with liposomal TRAIL. In both of the cell lines, the PL micelles showed equivalent cytotoxic effects to free PL after $24 \mathrm{~h}$ of treatment (Figure 4). On the one hand, sustained PL release from PL MILs may result in a lower effective concentration in the cell culture medium during treatment, but on the other hand, MILs could have increased cellular uptake of PL [26]. The combination treatment of 
PL in DMSO or PL MILs at $15 \mu \mathrm{M}$ and TRAIL liposomes exhibited a significantly higher apoptosis rate than each individual therapy alone (Figure 4).

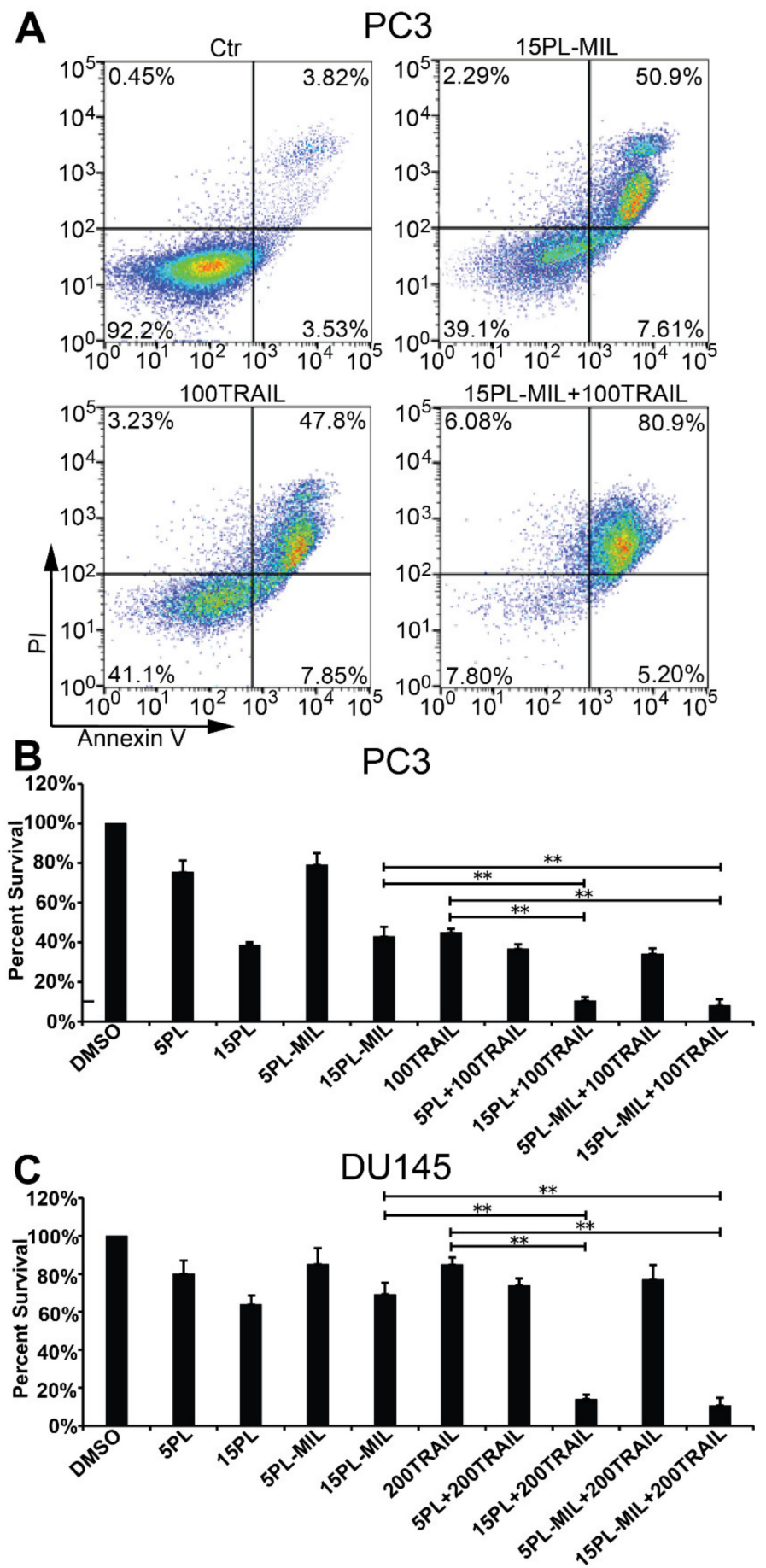

Figure 4. The anti-tumor effect of PL encapsulated MIL (PL-MIL) and liposomal tumor necrosis factor (TNF)-related apoptosis-inducing ligand (TRAIL). Prostate cancer cells PC3 (A,B) and DU145 (C) were treated with the indicated concentrations of PL in DMSO or PL-MIL (5 or $15 \mu \mathrm{M})$ and/or liposomal TRAIL (100 or $200 \mathrm{ng} / \mathrm{mL}$ ) in 12-well plates for $24 \mathrm{~h}$. The degree of cell apoptosis was measured using Annexin V/PI assay with flow cytometry. Representative flow cytometry dot plots from a PC3 experimental condition are shown. 


\section{Discussion}

In drug discovery, poor water solubility of drug candidates leads to low bioavailability and has long been a major reason for the failure of drug candidates [27]. Some approved drugs with low water solubility suffer from low permeability, rapid metabolism and clearance from the body. New solubilization technologies are needed for these existing drugs and for the majority of the molecules in the discovery pipeline to improve their efficacy, safety and patient compliance. As a promising drug carrier, polymeric micelles have been extensively pursued, owing to their ability to solubilize hydrophobic drugs within their hydrophobic core [19]. However, their clinical translation has been hampered by low in vivo stability due to polymer dissociation upon dilution in blood following systematic administration, and clearance by the immune system [28,29]. Strategies being explored to increase micellar stability with the goal of improving drug delivery mostly fall into two categories: covalent crosslinking to form covalent bonds in micelles, and noncovalent crosslinking to enhance the intra-micelle interaction via electrostatic interaction and hydrogen bonding [30,31]. However, these approaches may increase complexity in the large-scale manufacturing of micelles. Moreover, they may not prevent micelle molecules from binding to serum proteins-another major reason for micelle dissociation in the blood circulation $[20,32]$.

In this research, we encapsulated PL-loaded micelles into liposomes as visualized by cryo-TEM. Sustained drug release from the complex MIL structure was achieved in contrast to rapid release from free PL micelles. The MILs also increased the solubility of PL, potentially allowing the use of higher concentrations for both in vitro and in vivo applications. Since micelles have been used to solubilize numerous hydrophobic small molecules, MIL may be further explored as a general delivery vehicle for water-insoluble drugs.

While this current study was conducted, other researchers have reported efforts to encapsulate micelles into liposomes for the delivery of different hydrophobic compounds. Zhang et al. and Franzè et al. both demonstrated a more sustained drug release from MIL than from micelles as we found in our research. However, neither of these two other papers provided a cryo-TEM image or other direct evidence to verify that the micelles were actually inside the aqueous core of the liposomes $[33,34]$. While Romana et al. did provide a cryo-TEM image of a single liposome containing worm-like micelles inside, no ratio of liposomes containing micelles over all liposomes was reported [35].

Liposomes have been explored for the encapsulation of macromolecules such as DNA, RNA and protein for delivery, in addition to their more popular use in the delivery of small molecules [36,37]. However, the loading efficiency of macromolecules into the aqueous core of liposomes has been less satisfactory, due to the large size of macromolecules and the slow diffusion rate during the encapsulation process [38-40]. In our preparation of MILs, as revealed by cryo-TEM, $\sim 25 \%$ of all liposomes trapped micelles inside via passive drug loading. This encapsulation efficiency is lower than that for small drug loading where almost all the liposomes encapsulate a useful amount of drug. To further increase the encapsulation efficiency, electrostatic attraction, hydrogen bonding and even covalent bonding between micelles and liposomes may be explored [38].

\section{Materials and Methods}

\subsection{Key Materials}

The amphiphilic polymer PEG-PDLLA (PEG average Mn 2000, PDLLA average Mn 5000 ) used to prepare polymeric micelles was obtained from Sigma-Aldrich (St. Louis, MO, USA). Lipids for liposome preparation including Egg phosphatidylcholine (PC), cholesterol and 1,2-distearoyl-sn-glycero-3-phosphoethanolamine-N-[(polyethylene glycol)-2000] (DSPE-PEG) was obtained from Avanti Polar Lipids (Alabaster, AL, USA). Recombinant human TRAIL was purchased from Peprotech (Rocky Hill, NJ, USA). Liposomal TRAIL was prepared following our previously published methods [4,5]. Human prostate cancer PC3 and DU145 cells were obtained from American Type Culture Collection (ATCC) (Rockville, MD, USA) and were cultured in F-12k and EMEM medium, respectively, with $10 \%$ FBS. 


\subsection{Preparation of Micelles}

The PL micelles were made using a solvent evaporation method [41]. Briefly, $10 \mathrm{mg}$ PEG-PDLLA and $2 \mathrm{mg}$ PL was dissolved in $6 \mathrm{~mL}$ acetonitrile before adding $2 \mathrm{~mL}$ of deionized (DI) water. Acetonitrile was mostly removed on a rotary evaporator. The resulting suspension was then dialyzed against 2 L DI water saturated with PL overnight to remove the organic solvent completely. The resulting mixture was filtered through a $0.22 \mu \mathrm{m}$ syringe filter before being analyzed by ZetaSizer and TEM.

\subsection{Preparation of Micelle-in-Liposomes (MILs)}

MILs were prepared using a lipid film hydration method that is widely used to prepare liposomes [42]. Instead of using a buffer, a highly concentrated micelle suspension was used to hydrate the lipid film prepared with a molar composition of Egg PC:Cholesterol:DSPE-PEG $=64 \%: 32 \%: 4 \%$. The hydration was allowed to proceed for one hour at room temperature before the mixture was extruded through a $200 \mathrm{~nm}$ polycarbonate membrane 10 times. The resulting MILs were then purified with SEC integrated with fast protein liquid chromatography (FPLC) to remove the non-encapsulated micelles. PL content in the purified MILs was quantified by HPLC using gradient conditions: acetonitrile:water:trifluoroacetic acid (20:80:0.01) to (80:20:0.01) over $20 \mathrm{~min}$. A standard curve of $\mathrm{PL}$ at known concentrations was established for the measurement. Size distribution and morphology of the MILs was analyzed by Zetasizer and cryo-TEM.

\subsection{Drug Release Test}

One milliliter of purified PL micelles or PL MILs was placed in a dialysis bag with molecular weight cut off (MWCO) of $3.5 \mathrm{kD}$ against $200 \mathrm{~mL}$ of $\mathrm{pH} 7.0$ PBS buffer containing $0.5 \%$ Tween 20 at $37^{\circ} \mathrm{C}$. Released PL in the buffer was sampled over time and mixed with acetonitrile before being analyzed with HPLC using the HPLC conditions described above.

\subsection{Cell Apoptosis Assay}

Human prostate cancer cells PC3 and DU145 were seeded in 12-well plates at an initial density of $10^{5}$ cells per well, $24 \mathrm{~h}$ before treatment. Media was changed immediately before treatment. Cells were incubated with PL and PL MILs at 5 or $15 \mu \mathrm{M}$, or liposomal TRAIL at $100 \mathrm{ng} / \mathrm{mL}$ for PC 3 cells and $200 \mathrm{ng} / \mathrm{mL}$ for DU145 cells, or both MILs and liposomal TRAIL at these concentrations, for $24 \mathrm{~h}$ before analysis by Annexin V/Propidium Iodide (PI) apoptosis assay using a Guava ${ }^{\circledR}$ easyCyte ${ }^{\mathrm{TM}} 11 \mathrm{HT}$ flow cytometer (MilliporeSigma, Burlington, MA, USA) to quantify the proportion of viable cells.

\section{Conclusions}

We have developed a novel type of complex nanomaterial, MIL, and demonstrated its potential to formulate and deliver hydrophobic anticancer agents using PL as a model drug. Potent apoptotic effects of PL MILs in combination with liposomal TRAIL were observed in prostate cancer cells. The MILs provide a new approach for the delivery of water insoluble anticancer agents, which can be used either alone or in combination with TRAIL to promote its cancer-specific apoptotic effects. As MILs exhibited a much more sustained drug-release property than micelles in physiologically relevant buffers, MILs hold great promise to prolong the plasma life of micelles in vivo by containing the micelles inside liposomes before reaching their target.

Author Contributions: Conceptualization, Z.Z. and M.R.K.; methodology, Z.Z. and M.R.K.; investigation, Z.Z. and S.B.P.; writing-original draft preparation, Z.Z.; writing-review and editing, M.R.K.; supervision, M.R.K.; funding acquisition, M.R.K. All authors have read and agreed to the published version of the manuscript.

Funding: This research was funded by National Institutes of Health, grant number R01CA203991.

Institutional Review Board Statement: Not applicable.

Informed Consent Statement: Not applicable. 
Data Availability Statement: The data that support the findings of this study are available from the authors upon request.

Conflicts of Interest: The authors declare no conflict of interest.

\section{References}

1. Bellail, A.C.; Qi, L.; Mulligan, P.; Chhabra, V.; Hao, C. TRAIL agonists on clinical trials for cancer therapy: The promises and the challenges. Rev. Recent Clin. Trials 2009, 4, 34-41. [CrossRef] [PubMed]

2. Ashkenazi, A.; Pai, R.C.; Fong, S.; Leung, S.; Lawrence, D.A.; Marsters, S.A.; Blackie, C.; Chang, L.; McMurtrey, A.E.; Hebert, A.; et al. Safety and antitumor activity of recombinant soluble Apo2 ligand. J. Clin. Investig. 1999, 104, 155-162. [CrossRef] [PubMed]

3. Chandrasekaran, S.; Chan, M.F.; Li, J.; King, M.R. Super natural killer cells that target metastases in the tumor draining lymph nodes. Biomaterials 2016, 77, 66-76. [CrossRef] [PubMed]

4. Jyotsana, N.; Zhang, Z.; Himmel, L.E.; Yu, F.; King, M.R. Minimal dosing of leukocyte targeting TRAIL decreases triple-negative breast cancer metastasis following tumor resection. Sci. Adv. 2019, 5, eaaw4197. [CrossRef] [PubMed]

5. Mitchell, M.J.; Wayne, E.; Rana, K.; Schaffer, C.B.; King, M.R. TRAIL-coated leukocytes that kill cancer cells in the circulation. Proc. Natl. Acad. Sci. USA 2014, 111, 930-935. [CrossRef] [PubMed]

6. Wayne, E.C.; Chandrasekaran, S.; Mitchell, M.J.; Chan, M.F.; Lee, R.E.; Schaffer, C.B.; King, M.R. TRAIL-coated leukocytes that prevent the bloodborne metastasis of prostate cancer. J. Control. Release 2016, 223, 215-223. [CrossRef]

7. Ortiz-Otero, N.; Clinch, A.B.; Hope, J.; Wang, W.; Reinhart-King, C.A.; King, M.R. Cancer associated fibroblasts confer shear resistance to circulating tumor cells during prostate cancer metastatic progression. Oncotarget 2020, 11, 1037-1050. [CrossRef]

8. Ortiz-Otero, N.; Marshall, J.R.; Lash, B.; King, M.R. Chemotherapy-induced release of circulating-tumor cells into the bloodstream in collective migration units with cancer-associated fibroblasts in metastatic cancer patients. BMC Cancer 2020, 20, 1-13. [CrossRef]

9. Ortiz-Otero, N.; Marshall, J.R.; Lash, B.W.; King, M.R. Platelet mediated TRAIL delivery for efficiently targeting circulating tumor cells. Nanoscale Adv. 2020. [CrossRef]

10. Trivedi, R.; Mishra, D.P. Trailing TRAIL Resistance: Novel Targets for TRAIL Sensitization in Cancer Cells. Front. Oncol. 2015, 5, 69. [CrossRef]

11. De Wilt, L.H.; Kroon, J.; Jansen, G.; De Jong, S.; Peters, G.J.; Kruyt, F.A.E. Bortezomib and TRAIL: A perfect match for apoptotic elimination of tumour cells? Crit. Rev. Oncol. Hematol. 2013, 85, 363-372. [CrossRef] [PubMed]

12. Dorsey, J.F.; Mintz, A.; Tian, X.; Dowling, M.L.; Plastaras, J.P.; Dicker, D.T.; Kao, G.D.; El-Deiry, W.S. Tumor necrosis factor-related apoptosis-inducing ligand (TRAIL) and paclitaxel have cooperative in vivo effects against glioblastoma multiforme cells. Mol. Cancer Ther. 2009, 8, 3285-3295. [CrossRef] [PubMed]

13. Hunter, T.B.; Manimala, N.J.; Luddy, K.A.; Catlin, T.; Antonia, S.J. Paclitaxel and TRAIL synergize to kill paclitaxel-resistant small cell lung cancer cells through a caspase-independent mechanism mediated through AIF. Anticancer Res. 2011, 31, 3193-3204. [PubMed]

14. Shanker, A.; Brooks, A.D.; Tristan, C.A.; Wine, J.W.; Elliott, P.J.; Yagita, H.; Takeda, K.; Smyth, M.J.; Murphy, W.J.; Sayers, T.J. Treating metastatic solid tumors with bortezomib and a tumor necrosis factor-related apoptosis-inducing ligand receptor agonist antibody. J. Natl. Cancer Inst. 2008, 100, 649-662. [CrossRef] [PubMed]

15. Li, J.; Sharkey, C.C.; King, M.R. Piperlongumine and immune cytokine TRAIL synergize to promote tumor death. Sci. Rep. 2015, 5, 9987. [CrossRef]

16. Raj, L.; Ide, T.; Gurkar, A.U.; Foley, M.A.; Schenone, M.; Li, X.; Tolliday, N.J.; Golub, T.R.; Carr, S.A.; Shamji, A.F.; et al. Selective killing of cancer cells by a small molecule targeting the stress response to ROS. Nat. Cell Biol. 2011, 475, 231-234. [CrossRef]

17. Sharkey, C.C.; Li, J.; Roy, S.; Wu, Q.; King, M.R. Two-stage nanoparticle delivery of piperlongumine and tumor necrosis factor-related apoptosis-inducing ligand (TRAIL) anti-cancer therapy. Technology 2016, 4, 60-69. [CrossRef]

18. Kwon, G.S.; Okano, T. Polymeric micelles as new drug carriers. Adv. Drug Deliv. Rev. 1996, 21, 107-116. [CrossRef]

19. Jones, M.-C.; Leroux, J.-C. Polymeric micelles-A new generation of colloidal drug carriers. Eur. J. Pharm. Biopharm. 1999, 48, 101-111. [CrossRef]

20. Owen, S.C.; Chan, D.P.; Shoichet, M.S. Polymeric micelle stability. Nano Today 2012, 7, 53-65. [CrossRef]

21. Senior, J.; Delgado, C.; Fisher, D.; Tilcock, C.; Gregoriadis, G. Influence of surface hydrophilicity of liposomes on their interaction with plasma protein and clearance from the circulation: Studies with poly(ethylene glycol)-coated vesicles. Biochim. Biophys. Acta Biomembr. 1991, 1062, 77-82. [CrossRef]

22. Gabizon, A.; Martin, F. Polyethylene Glycol-Coated (Pegylated) Liposomal Doxorubicin. Drugs 1997, 54, 15-21. [CrossRef] [PubMed]

23. Szoka, F.; Olson, F.; Heath, T.; Vail, W.; Mayhew, E.; Papahadjopoulos, D. Preparation of unilamellar liposomes of intermediate size $(0.1-0.2 \mu \mathrm{m})$ by a combination of reverse phase evaporation and extrusion through polycarbonate membranes. Biochim. Biophys. Acta Biomembr. 1980, 601, 559-571. [CrossRef]

24. Aodah, A.; Pavlik, A.; Karlage, K.; Myrdal, P.B. Preformulation Studies on Piperlongumine. PLoS ONE 2016, 11 , e0151707. [CrossRef] [PubMed]

25. Jin, H.-O.; Lee, Y.-H.; Park, J.-A.; Lee, H.-N.; Kim, J.-H.; Kim, J.-Y.; Kim, B.; Hong, S.-E.; Kim, H.-A.; Kim, E.-K.; et al. Piperlongumine induces cell death through ROS-mediated CHOP activation and potentiates TRAIL-induced cell death in breast cancer cells. J.Cancer Res. Clin. Oncol. 2014, 140, 2039-2046. [CrossRef] [PubMed] 
26. Chen, H.; Kim, S.; Li, L.; Wang, S.; Park, K.; Cheng, J.-X. Release of hydrophobic molecules from polymer micelles into cell membranes revealed by Forster resonance energy transfer imaging. Proc. Natl. Acad. Sci. USA 2008, 105, 6596-6601. [CrossRef]

27. Kalepu, S.; Nekkanti, V. Insoluble drug delivery strategies: Review of recent advances and business prospects. Acta Pharm. Sin. $B$ 2015, 5, 442-453. [CrossRef]

28. Oerlemans, C.; Bult, W.; Bos, M.; Storm, G.; Nijsen, J.F.W.; Hennink, W.E. Polymeric Micelles in Anticancer Therapy: Targeting, Imaging and Triggered Release. Pharm. Res. 2010, 27, 2569-2589. [CrossRef]

29. Kim, S.; Shi, Y.; Kim, J.Y.; Park, K.; Cheng, J.-X. Overcoming the barriers in micellar drug delivery: Loading efficiency, in vivostability, and micelle-cell interaction. Expert Opin. Drug Deliv. 2009, 7, 49-62. [CrossRef]

30. Talelli, M.; Barz, M.; Rijcken, C.J.F.; Kiessling, F.; Hennink, W.E.; Lammers, T. Core-crosslinked polymeric micelles: Principles, preparation, biomedical applications and clinical translation. Nano Today 2015, 10, 93-117. [CrossRef]

31. Yang, C.; Attia, A.B.E.; Tan, J.P.; Ke, X.; Gao, S.; Hedrick, J.L.; Yang, Y.-Y. The role of non-covalent interactions in anticancer drug loading and kinetic stability of polymeric micelles. Biomaterials 2012, 33, 2971-2979. [CrossRef] [PubMed]

32. Lu, J.; Owen, S.C.; Shoichet, M.S. Stability of Self-Assembled Polymeric Micelles in Serum. Macromolecules 2011, 44, 6002-6008. [CrossRef] [PubMed]

33. Zhang, W.; Li, C.; Jin, Y.; Liu, X.; Wang, Z.; Shaw, J.P.; Baguley, B.C.; Wu, Z.; Liu, J. Multiseed liposomal drug delivery system using micelle gradient as driving force to improve amphiphilic drug retention and its anti-tumor efficacy. Drug Deliv. 2018, 25, 611-622. [CrossRef] [PubMed]

34. Franzè, S.; Musazzi, U.M.; Minghetti, P.; Cilurzo, F. Drug-in-micelles-in-liposomes (DiMiL) systems as a novel approach to prevent drug leakage from deformable liposomes. Eur. J. Pharm. Sci. 2019, 130, 27-35. [CrossRef] [PubMed]

35. Romana, B.; Hassan, M.; Sonvico, F.; Pereira, G.G.; Mason, A.F.; Thordarson, P.; Bremmell, K.E.; Barnes, T.J.; Prestidge, C.A. A liposome-micelle-hybrid (LMH) oral delivery system for poorly water-soluble drugs: Enhancing solubilisation and intestinal transport. Eur. J. Pharm. Biopharm. 2020, 154, 338-347. [CrossRef]

36. Weiner, A.L. Liposomes for Protein Delivery: Selecting Manufacture and Development Processes. Immunomethods 1994, 4, 201-209. [CrossRef]

37. Xu, Y.; Szoka, F.C. Mechanism of DNA Release from Cationic Liposome/DNA Complexes Used in Cell Transfection. Biochemistry 1996, 35, 5616-5623. [CrossRef]

38. Colletier, J.-P.; Chaize, B.; Winterhalter, M.; Fournier, D. Protein encapsulation in liposomes: Efficiency depends on interactions between protein and phospholipid bilayer. BMC Biotechnol. 2002, 2, 9. [CrossRef]

39. Xu, X.; Costa, A.; Burgess, D.J. Protein Encapsulation in Unilamellar Liposomes: High Encapsulation Efficiency and A Novel Technique to Assess Lipid-Protein Interaction. Pharm. Res. 2012, 29, 1919-1931. [CrossRef]

40. Chaize, B.; Colletier, J.-P.; Winterhalter, M.; Fournier, D. Encapsulation of enzymes in liposomes: High encapsulation efficiency and control of substrate permeability. Artif. Cells Blood Substit. Biotechnol. 2004, 32, 67-75. [CrossRef]

41. Aliabadi, H.; Elhasi, S.; Mahmud, A.; Gulamhusein, R.; Mahdipoor, P.; Lavasanifar, A. Encapsulation of hydrophobic drugs in polymeric micelles through co-solvent evaporation: The effect of solvent composition on micellar properties and drug loading. Int. J. Pharm. 2007, 329, 158-165. [CrossRef] [PubMed]

42. Vemuri, S.; Rhodes, C. Preparation and characterization of liposomes as therapeutic delivery systems: A review. Pharm. Acta Helv. 1995, 70, 95-111. [CrossRef] 